\title{
A NEW RECOMBINANT ADENO-ASSOCIATED VIRUS (AAV)-BASED RANDOM PEPTIDE DISPLAY LIBRARY SYSTEM: INFECTION-DEFECTIVE AAV1.9-3 AS A NOVEL DETARGETED PLATFORM FOR VECTOR EVOLUTION*
}

\author{
KEI ADACHI and HIROYUKI NAKAI ${ }^{\dagger}$ \\ Department of Microbiology and Molecular Genetics \\ University of Pittsburgh School of Medicine \\ Pittsburgh, PA 15219, USA \\ ${ }^{\dagger}$ nakaih@pitt.edu
}

Received 11 July 2010

Revised 8 September 2010

Accepted 11 September 2010

\begin{abstract}
Directed evolution through genetic engineering of viral capsids followed by selection has emerged as a powerful means to create novel recombinant adeno-associated virus (rAAV) vectors with desired tropism and enhanced properties. One of the most effective approaches uses rAAV-based random peptide display libraries. Here we report a novel system based on an infection-defective rAAV1.9-3 as a platform for random peptide display, and show that biopanning of the libraries in vitro effectively identifies the peptides that restore and enhance rAAV transduction. rAAV1.9-3 has a genetically engineered AAV1 capsid with amino acids 445-568 being replaced with those of AAV9, and has been identified as a variant exhibiting significantly impaired infectivity and delayed blood clearance when infused into mice. In this study, we generated rAAV1.9-3 variant libraries in which 7- or 12-mer random peptides were expressed at the capsid amino acid position 590. Three rounds of positive selection for primary human dermal fibroblasts successfully identified new $\mathrm{rAAV}$-peptide variants that transduce them more efficiently than the prototype rAAV2. Thus our study demonstrates that an infection-defective rAAV variant serves as a novel detargeted platform for random peptide display libraries. We also describe a brief review of recent progress in rAAV-based random peptide display library approaches.
\end{abstract}

Keywords: Adeno-associated virus; gene therapy; directed evolution; random peptide display; capsid engineering.

\section{Introduction}

Recombinant adeno-associated virus (rAAV) vectors represent promising gene delivery vehicles and have become increasingly popular due to their high transduction

\footnotetext{
* Original research article.

${ }^{\dagger}$ Corresponding author.
} 
efficiency and safety. Until recently, the prototype rAAV vectors had been those based on AAV serotype 2 (AAV2), which exhibited a limited transduction efficiency in various types of cells. In the early 2000s, over a hundred different AAV serotypes and variants were identified from tissues of primates and other animals by PCRbased approaches (Arbetman et al., 2005; Gao et al., 2004 and 2002; Lochrie et al., 2006a; Mori et al., 2004; Schmidt et al., 2004). Since then, expanding availability of a wide array of different AAV capsids has significantly increased the utility of rAAV vectors. Vectors based on AAV serotype 8 or 9 have been shown to overcome the barriers faced by earlier-generation rAAV vectors and mediate robust transduction in various organs including the liver, heart, striated muscles and central nervous system (Foust et al., 2009; Ghosh et al., 2007; Inagaki et al., 2006; Pacak et al., 2006; Sarkar et al., 2006; Vandendriessche et al., 2007; Wang et al., 2005). Thus, the current rAAV vectors offer various advantages over other vectors in many aspects; however, the opportunity for further improvement remains, particularly in AAV capsid engineering to improve transduction efficiency, alter vector tropism for targeted gene delivery, and overcome pre-existing humoral immune responses that might neutralize vectors.

The capsid protein is the major determinant of the biological properties of rAAV vectors; therefore, rAAV research has been seeking to elucidate the AAV capsid structure-function relationships to better understand the biology of rAAV. The atomic structure of AAV VP3 capsid proteins has been determined in AAV serotypes 1, 2, 4, 5 and 8, and partially elucidated in AAV serotypes 6 and 9. Characteristic are the two finger-like projections that correspond to portions of the longest loop between the $\beta$-sheets $\mathrm{G}$ and $\mathrm{H}$ of the protein (i.e., the GH loop) (Fig. 1(a)). These two projections from adjacent $3 \mathrm{VP}$ proteins together form the three capsid protrusions around the icosahedral three-fold symmetry axes (three-fold protrusions) (Fig. 1(b)). As predicted by their topological locations, the three-fold protrusions play important roles in the interaction with cells and neutralizing antibodies. In AAV2, the positively charged three arginine residues (R487, R585 and R587) responsible for binding to heparan sulfate proteoglycan (HSPG), the primary cellular receptor for AAV2, reside near the peak of the three-fold protrusions (Kern et al., 2003) (Fig. 1(a)). In addition, some of the epitopes recognized by AAV2 capsid-directed antibodies have been mapped in this vicinity (Perabo et al., 2006a; Wobus et al., 2000). Moreover, domain swapping studies of AAV capsid proteins have revealed an important role of the three-fold capsid protrusions in mediating the robust hepatic transduction with rAAV8 and rAAV9 vectors in mice (Shen et al., 2007 and Kotchey et al., manuscript submitted). Furthermore, the amino acid residues at the three-fold symmetry axis are vastly diverse between naturally occurring serotypes/variants exhibiting distinct properties. Therefore, rational design approaches to alter the tropism by AAV capsid engineering has been directed to the three-fold protrusions. Successful approaches include ablation of the heparin binding ability of rAAV2 mutants by introducing R484E/R585E mutations, which results in detargeting the liver and redirecting the vector to the 


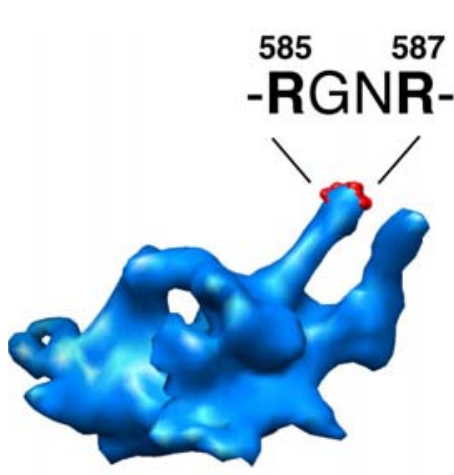

(a)

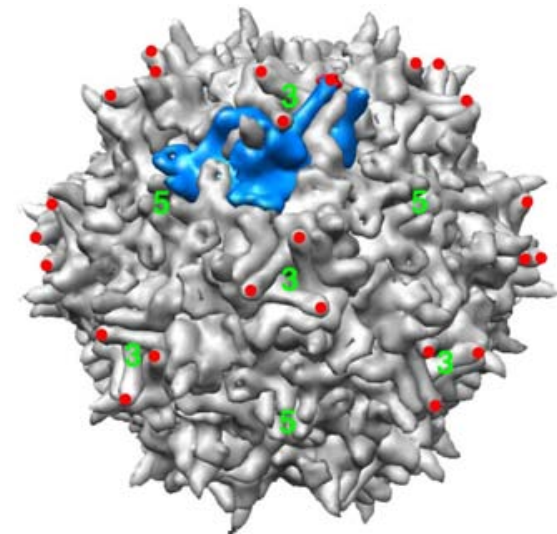

(b)

Fig. 1. Structure of AAV serotype 2. (a). Three-dimensional structure of AAV2 VP3 protein. The heparin binding motif, -RGNR-, at the peak of one of the finger-like protrusions is highlighted with red. (b). Structure of the AAV2 virion shell. A blue unit represents one of the 60 VP proteins that compose the virion. Red dots are the inner spikes of the three-fold capsid protrusions where the heparin binding motif resides and random peptides are preferentially displayed. The locations of the 3 and 5 -fold icosahedral symmetry axes are indicated with the corresponding numbers. The figures are created using UCSF Chimera.

heart (Kern et al., 2003; Muller et al., 2006), and incorporation of the RGD motifcontaining peptides at positions 447 or 587 (Girod et al., 1999) or at positions 584 or 588 (Shi and Bartlett, 2003) in the AAV2 capsid protrusions to target integrin receptors on the cell surface.

Although these approaches have yielded encouraging results, they require prior mechanistic knowledge about the functional domains within each capsid. In contrast, directed evolution approaches rely on the power of selection and require limited prior knowledge. Therefore, with limited understanding of the AAV capsid structure-function relationships, directed evolution would offer a more effective means to engineer proteins to create novel variants with desired properties superior over those of natural counterparts. The approach involves creation of libraries of AAV capsid variants diversified by DNA shuffling, error-prone PCR, random peptide insertion/replacement, or a combination of them, followed by multiple rounds of selection for a desired phenotype. To date, the directed evolution approach has successfully been employed to identify new rAAV variants that target various types of cells in vitro and several organs in vivo with various specificities (Excoffon et al., 2009; Grimm et al., 2008; Koerber et al., 2009; Li et al., 2008 and 2009; Maguire et al., 2009; Michelfelder et al., 2009 and 2007; Muller et al., 2003; Perabo et al., 2003; Sellner et al., 2008; Stiefelhagen et al., 2008; Waterkamp et al., 2006; Yang et al., 2009; Ying et al., 2010). It has also been employed to create stealth rAAV variants that evade host immune responses (Grimm et al., 2008; Maersch et al., 2010; Maheshri et al., 2006; Perabo et al., 2006a). 
In the rAAV-based random peptide display approaches, AAV2 has provided the most common platform for peptide display. In perspective of cell or organ targeting, it is important to achieve high specificity, as well as high efficiency of transduction. In this regard, the most common approach to attain both objectives is to express a peptide around position 587 in the AAV2 capsid three-fold protrusion, where the heparin binding motif R585-X-X-R587 resides. Peptide insertion into or near the RXXR motif could ablate the heparin binding ability; therefore, it can significantly attenuate natural tropism of rAAV2 and detarget the liver and spleen (Perabo et al., 2006b). However, it has been shown that ablation of heparin binding is not sufficient to achieve target cell-specific gene delivery (Michelfelder et al., 2009). Thus, rAAV2 does not necessarily represent the most desirable platform for peptide display and it will be vital to develop a new vector platform that is fully detargeted for retargeting only to a specific cell type.

In this study, to seek such a fully detargeted platform for rAAV-based peptide display, we explored the possibility that an infection-defective $\mathrm{AAV}$ variant could be exploited as a naturally detargeted platform for random peptide display. rAAV1.9-3 is an infection-defective variant we have identified. rAAV1.9-3 carries an AAV1 and AAV9 hybrid capsid in which amino acids 1-454, 455-567 and 568-736 are derived from AAV1, AAV9 and AAV1, respectively, and exhibits a substantial loss of infectivity in mice (Kotchey et al., manuscript submitted). Here we demonstrate that peptides selected from random peptide libraries can restore infectivity of the infection-defective rAAV1.9-3 and mediate efficient transduction in targeted cells in vitro, showing proof-of-principle of a new random peptide display library system based on an infection-defective rAAV.

\section{Materials and Methods}

\section{Construction of AAV plasmids}

The construction of pHLP1.9-3, an AAV helper plasmid for production of rAAV1.9-3 vectors has been described previously (Kotchey et al., manuscript submitted). Briefly, the 0.4-kb Bsp EI-Msc I DNA fragment within the AAV1 cap gene open reading frame (ORF) in the plasmid pHLP19-1 (AAV1 helper plasmid) (Grimm et al., 2003) was replaced with the corresponding region of the AAV9 cap gene to create pHLP1.9-3. Two silent mutations, A1767G and C1770T (the numbers represent nucleotide numbers of the AAV1 cap gene ORF), were introduced in the AAV1 cap gene to create a new Bam HI site therein. This results in the construction of pHLP1.9-3 Bam HI. pUC620 is a pUC119-based plasmid containing wild-type AAV2 genome (kindly provided by Avigen Inc., California), and has two Hind III sites and an Sph I site in the plasmid. The Hind III and Sph I sites within the pUC620 plasmid backbone were destroyed by restriction enzyme digestion, T4 DNA polymerase treatment followed by ligation with T4 DNA ligase, leaving unique Hind III site within the wild-type AAV2 viral genome to make 
pUC620-3. The resulting pUC620-3 has two Bam HI sites: one in the plasmid backbone and the other within the AAV2 rep gene ORF. Two silent mutations, $\mathrm{C} 729 \mathrm{~T}$ and C738T (the numbers represent nucleotide numbers of the AAV2 rep gene ORF), were introduced in the AAV2 rep gene ORF to remove the Bam HI site and make the Stu I site dcm-unmethylated, and the other Bam HI site in the plasmid backbone was removed. This created pUC620-3 $\triangle$ Bam HI. pAAV1HB1 is a pUC630-3 derivative with the AAV2 cap gene being replaced with the AAV1 cap gene from pHLP19-1. To construct pAAV1.9-3 BamHI, the AAV1 cap gene in pAAV1-HB1 was replaced with that of pHLP1.9-3 Bam HI. The plasmid pAAV1.9-3 BamHI has unique Bam HI and Sph I sites in the AAV1.9-3 cap gene, between which double-stranded oligonucleotides containing random 7 or 12-mer peptide-coding sequences were inserted to create the random peptide display rAAV1.9-3 library plasmids (Fig. 2). We chose 7 - and 12-mers for random peptide display because these two peptide lengths have commonly been applied to phage display random peptide libraries exemplified by $\mathrm{Ph} . \mathrm{D} .{ }^{\mathrm{TM}}$ Phage Display Peptide Library Kits from New England Biolabs, and because previously published rAAV-based random peptide display studies were succesful with 7-mers (see Table 3 below). pHLP1.9-3 Bam HI, an AAV helper plasmid that serves as a platform for the production of rAAV1.9-3 vectors expressing 7- or 12-mer peptides on their virion shells, was created by replacing the AAV1.9-3 cap gene in pHLP1.9-3 with

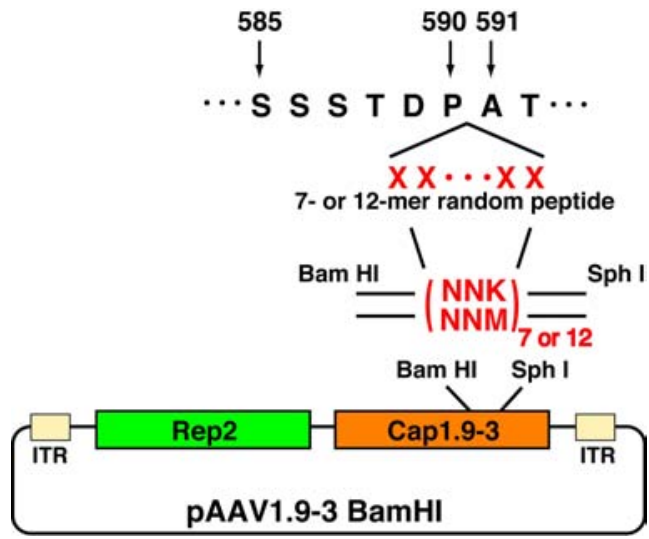

(a)

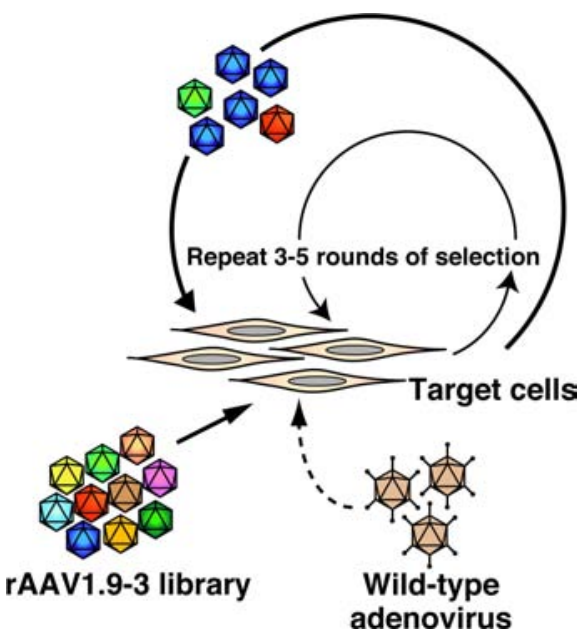

(b)

Fig. 2. Creation and biopanning of the rAAV1.9-3-based random peptide display libraries. (a). rAAV1.9-3-based random peptide display library system. Double-stranded oligonucleotides containing random 7- or 12-mer peptide-coding sequence are inserted between AAV1.9-3 amino acid positions 590 and 591 in the plasmid pAAV1.9-3 BamHI to make library plasmids. (b). Schematic representation of the biopanning procedure. 
that of pAAV1.9-3 BamHI. Plasmid pEMBL-CMV-GFP for double-stranded AAVCMV-GFP vector production was kindly provided by Dr. Xiao Xiao, University of North Carolina at Chapel Hill. Plasmid pAAV-CMV-GFP for single-stranded AAV-CMV-GFP production was as follows. A 1.9-kb fragment containing the entire CMV-GFP expression cassette was PCR-amplified from pEMBL-CMV-GFP using a primer set (52-97 CMV-GFP For: 5'-AGTGGAATTCACGCGTGGATCT-3' , and 52-97 CMVGFP Rev: 5'-TTAGGGTTACCATTGATGAGTTTGGACAAACCAC$3^{\prime}$ ) and cloned between Mfe I and Bst EII sites of pAAV $\Delta$ BamHI (Nakai et al., 2000b). The resulting pAAV-CMV-GFP contains a 1.0-kb non-coding sequence of the human genome (Chr 6:74230878-74231923) upstream of the CMV-GFP expression cassette as a stuffer. Plasmid pAAV-CMV-lacZ was described previously (Nakai et al., 2005).

Construction of the plasmids for rAAV1.9-3-based random peptide display libraries was as follows. To reduce the probability of having a stop codon within peptide-coding oligonucleotides being incorporated in the AAV1.9-3 capsid, we used the NNK codon scheme, where K represents G or T. In this design, there are 32 different codons that encode all the 20 amino acids and only one stop codon. The following oligos were synthesized for the creation of the plasmid libraries used in the study (the Bam HI site is in bold and the Sph I site is underlined): $5^{\prime}$-GCACGGATCCT(NNK) ${ }_{12}$ GCGACCGGAGATGTGCATGC-3'; 60-128 7-mer For, 5'-GCACGGATCCT(NNK) ${ }_{7}$ GCGACCGGAGATGTGCATGC-3'; 60 128 Rev, 5'-CATAGCATGCACATCTCCGGTCGC-3'. One hundred picomoles each of the forward and reverse primers were annealed in $40 \mu \mathrm{l}$ of 1 x New England BioLabs (NEB) Buffer 2 by heating to $70^{\circ} \mathrm{C}$ followed by slow cooling. dNTP was added to the reaction mixture at the final concentration of $1.25 \mathrm{mM}$ and incubated at $37^{\circ} \mathrm{C}$ for 1 hour in the presence of 10 units of Klenow fragment with no $3^{\prime}$ to $5^{\prime}$ exonuclease activity (NEB) in a final volume of $50 \mu$ l. The synthesized double-stranded DNA was digested with Bam HI and Sph I, and purified by $3.0 \%$ agarose gel electrophoreses followed by DNA extraction from the gel using Qiagen Gel Extraction kit. pAAV1.9-3 BamHI plasmid backbone was prepared by Bam HI and Sph I digestion of pAAV1.9-3 Bam HI followed by agarose gel fractionation. The Bam HI-Sph I-digested double-stranded oligos containing random 7- or 12mer peptide-coding sequence were ligated to $200 \mathrm{ng}$ of the linearized pAAV1.9-3 BamHI plasmid backbone at a backbone to insert DNA molar ratio of 1:10 in $80 \mu \mathrm{l}$ reaction mixture containing T4 DNA ligase. The ligated DNA was purified by phenol-chloroform extraction, precipitated with isopropanol in the presence of $0.25 \mathrm{M}$ potassium acetate and $10 \mu \mathrm{g}$ of glycogen, and dissolved in $12 \mu \mathrm{l}$ of water. ElectroMax BH10B competent Escherichia coli was transformed with $3 \mu \mathrm{l}$ of the ligated products, and plated on LB agar plates supplemented with $50 \mu \mathrm{g} / \mathrm{ml}$ of ampicillin, yielding approximately $10^{6}$ transformants on the plates. Frequencies of the occurrence of a stop codon within the random peptide-coding sequences were $8 \%$ ( 2 of 24 sequenced clones) and $38 \%$ ( 8 of 21 sequenced clones) in the 7 - and 12-mer libraries, respectively. 


\section{Cells}

Human kidney embryonic (HEK) 293 cells were purchased from Stratagene. Primary normal human dermal fibroblasts (HDF), human cervical cancer cell line HeLa cells, human malignant glioma cell line U87-MG cells and human fibrosarcoma cell line HT1080 cells were obtained from American Type Culture Collection (ATCC). HEK293 cells and HeLa cells were grown in Dulbecco's modified Eagle's medium (DMEM, Lonza) supplemented with 10\% fetal bovine serum (FBS), L-glutamine and penicillin-streptomycin. U87-MG cells and HT1080 cells were maintained in Eagle's minimum essential medium (EMEM, Lonza) supplemented with $10 \%$ FBS and penicillin-streptomycin. HDF were grown in fibroblasts growth media (FGM bullet kit, Lonza) supplemented with $2 \%$ FBS.

\section{$r A A V$ production}

Production and purification of rAAV vectors was described previously (Burton et al., 1999). Briefly, we used an adenovirus-free 3 plasmid transfection method for rAAV vector production in HEK293 cells, and performed 2 cycles of cesium chloride ultracentrifugation for purification. For rAAV1.9-3 random peptide display library production, we used 2 plasmids, pAAV1.9-3 BamHI 7- or 12-mer peptide library plasmid and adenovirus helper plasmid (pHelper, Stratagene), at a 0.01-0.1 to 1 ratio and purified rAAV libraries in the same manner. rAAV titers were determined by a quantitative dot blot assay. rAAV1.9-3-peptide libraries were produced on a small scale $(2 \times 10 \mathrm{~cm}$ dishes $)$ or on a large scale $\left(25 \times 225 \mathrm{~cm}^{2}\right.$ flasks $)$. Small scale preparations were used as unpurified crude lysates of HEK293 cells. The large scale preparations were purified by two cycles of cesium chloride ultracentrifugation as previously described (Burton et al., 1999).

\section{In vitro biopanning}

The biopanning procedure we used is schematically presented in Fig. 2. Briefly, one million HEK293 cells or HDF (passage 5) were seeded on $10 \mathrm{~cm}$ dishes one day before the first round biopanning. At day 0, cells were infected with rAAV peptide display libraries at a multiplicity of infection (MOI) of 1000 in $4 \mathrm{ml}$ of the complete growth medium. After 1-hour incubation, $6 \mathrm{ml}$ of the complete medium was added, and incubated for 2 days. Forty-eight hours after library inoculation, rAAV particles were completely washed out with phosphate-buffered saline (PBS), and cells were infected with wild-type adenovirus type 5 at a MOI of 10 in $2 \mathrm{ml}$ of the corresponding plain medium without any supplements for 30 minutes, then $10 \mathrm{ml}$ of the complete medium was added. The cells were harvested $3-5$ days after adenovirus infection, suspended in $100 \mu \mathrm{l}$ of PBS, and underwent freeze-thaw three times. Crude cell lysate containing rAAV particles was recovered by centrifugation, and heat-treated at $56^{\circ} \mathrm{C}$ for 1 hour to inactivate adenovirus. Approximately half of the crude cell lysate was used for the next round of biopanning. After three 
rounds of positive selection, selectively amplified rAAV viral genome DNA was extracted from viral particles and subjected to PCR using primers 63-99-10 For (5'-AGAGAGCGCCGGAAGAGACAACGTGGATGCG-3') and 63-99-6 Rev (5'TCTCTATCTTGCCACACCATGCCA-3') to recover the selected peptide-coding sequences. The PCR products were then cloned into pCR2.1-TOPO (Invitrogen) and sequenced. The identified peptide-coding DNA fragments were inserted into pHLP1.9-3 Bam HI between the Bam HI and Sph I sites.

\section{In vitro cell transduction assays}

Cells seeded in 12, 24 or 96-well plates were infected with rAAV vectors expressing the lacZ or GFP gene at the indicated MOIs for 24 hours. Seventy-two hours postinfection (p.i.), transduction efficiencies were determined in the following manners. For the cells infected with AAV-CMV-lacZ vector, the transgene expression levels in cells were assessed by X-Gal staining and bacterial $\beta$-galactosidase-specific enzymelinked immunosorbent assay ( $\beta$-gal ELISA) using a kit from Roche Diagnostic as previously described (Nakai et al., 2000a). Protein concentrations of cell lysates were determined by DC Protein Assay Kit (Bio-Rad) and used to normalize the values obtained by the $\beta$-gal ELISA (Nakai et al., 2000a). For the cells infected with AAVCMV-GFP, they were observed under a fluorescence microscope and underwent flow cytometric analysis using a BD FACS Calibur system (Becton Dickinson). At least 5000 cells were counted in the flow cytometry. Heparin inhibition assay was performed as previously described with a modification (Rabinowitz et al., 2004). Briefly, cells were seeded in 24-well plates and incubated with complete medium supplemented with 0,10 , and $50 \mu \mathrm{g} / \mathrm{ml}$ of heparin sodium salt (Sigma) for 1 hour before $\mathrm{rAAV}$ vector infection. $\mathrm{rAAV}$ vectors were also incubated in complete medium supplemented with heparin at indicated concentrations at $37^{\circ} \mathrm{C}$ for 1 hour before use. Then cells preincubated with heparin were infected with rAAV vectors pretreated with heparin, and transduction efficiencies were determined 72 hours postinfection as described above.

\section{Results}

\section{rAAV1.9-3 exhibited significantly impaired infectivity}

rAAV1.9-3 was originally identified as a rAAV1 and rAAV9 hybrid variant that showed significantly delayed blood clearance when infused into mice (blood clearance half-life $=\sim 24$ hours) (Kotchey et al., manuscript submitted). Our in vivo study has demonstrated that this variant failed to mediate transduction in the liver and other organs in mice except for cardiac transduction at a very low level, indicating the infection-defective nature of this variant. Here we investigated whether rAAV1.9-3 is also defective in transducing in vitro cultured cells. HEK293, HeLa, U87-MG, and HT1080 cells were infected with double-stranded (ds) AAV2-CMV-GFP or dsAAV1.9-3-CMV-GFP at MOIs ranging from $10^{2}$ to $10^{4}$ 
or $10^{5}$, respectively. The transduction efficiencies were determined by fluorescent microscopy and flow cytometry. The rAAV2 vector was chosen as a reference control due to its broad tropism and relatively high transduction efficiency in many cell types in vitro, and the above 4 cell lines were chosen because they are highly permissive to rAAV2 vectors. The result showed that dsAAV1.9-3-CMV-GFP barely transduced HeLa, U87-MG, and HT1080 cells at a MOI of $10^{5}$, and their transduction efficiencies were at least 800 to 900 fold lower than those attainable with a 10-fold lower dose of the reference control, rAAV2 (Fig. 3). rAAV1.9-3 transduced HEK293 cells to some extent at a MOI of $10^{5}$; however, the transduction efficiency was only comparable to that achieved by rAAV2 at MOI of $10^{2}$, indicating that the transduction ability of rAAV1.9-3 should be approximately $1 / 1000$ of that of

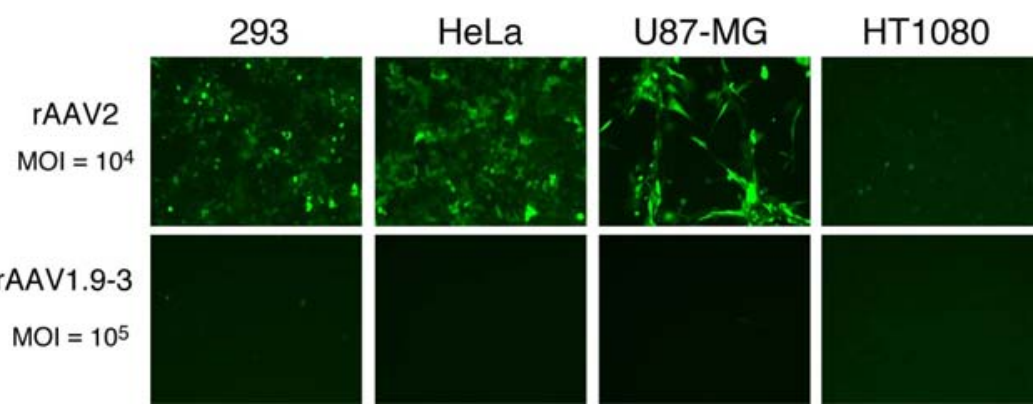

(a)

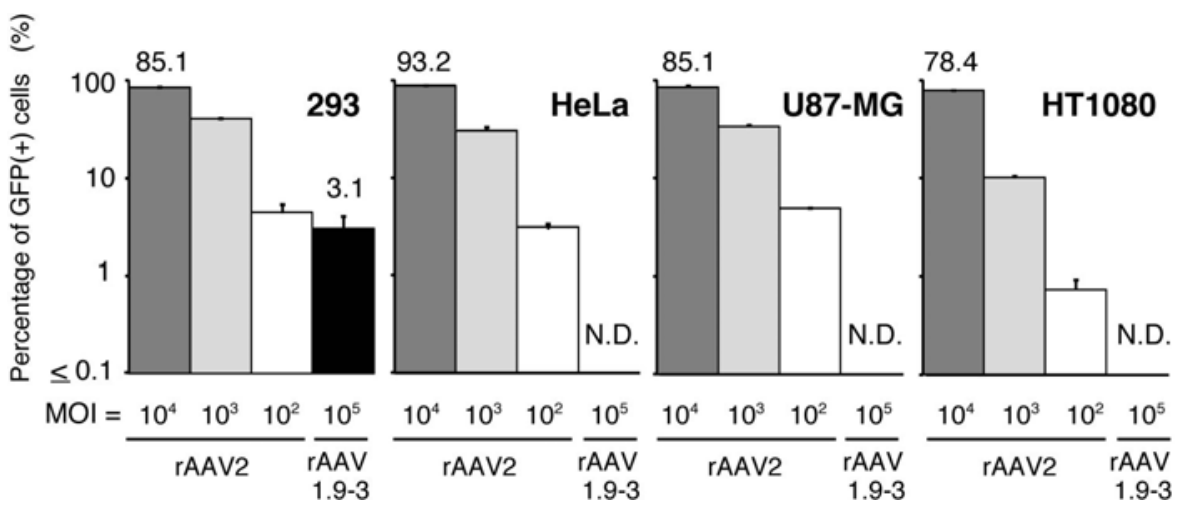

(b)

Fig. 3. Transduction efficiencies of rAAV2 and rAAV1.9-3 in various cells. (a). Cells in 96-well plates were infected with dsAAV2-CMV-GFP (upper panel) or dsAAV1.9-3-CMV-GFP (lower panel) vector at an MOI of $10^{4}$ or $10^{5}$, respectively. Three days post-infection, GFP expression was assessed by fluorescence microscopy. (b). Cells in 12-well plates were infected with dsAAV2-CMV-GFP or dsAAV1.9-3-CMV-GFP vector at the indicated MOIs in triplicate. Three days after infection, transduction efficiencies were determined by flow cytometry. Vertical bars indicate standard deviations. N.D., not detected. 
rAAV2. Thus our in vitro observation in this study together with our previous in vivo observation (Kotchey et al., manuscript submitted) strongly indicate that the default phenotype of rAAV1.9-3 is infection-defective.

\section{Biopanning of rAAV1.9-3 peptide display libraries on HEK293 cells identified $r A A V 1.9$-3-peptide variants that were selectively amplified by three-rounds of positive selection}

To assess our hypothesis that infection-defective rAAV1.9-3 serves as a platform for random peptide display, we performed biopanning of rAAV1.9-3-based 7- and 12-mer random peptide display libraries on HEK293 cells. We produced 3 each different lots of 7 - and 12-mer libraries on a small scale. Following three rounds of positive selection, rAAV1.9-3 variants carrying particular peptide sequences were selectively amplified from the rAAV library preparations (Table 1 ). In addition to the peptides in the expected lengths (i.e., 7 mers or 12 mers), shorter-than-expected peptide sequences could also be selected by the biopanning due to the potential presence of truncated peptide-coding sequences in the libraries. A consensus sequence, $\operatorname{RXXXRX}(\mathrm{A} / \mathrm{P})$, was shared with 8 peptides, and became enriched in multiple independent experiments using different lots of libraries (Table 1). It should be noted that all selected peptides had basic isoelectric points (pIs) of 9.7-12.5.

\section{rAAV1.9-3 vectors displaying HEK293-targeting peptides restored the ability of $r A A V 1.9-3$ to transduce HEK293 cells}

We produced rAAV1.9-3-HEK293-peptide vectors expressing the bacterial lacZ gene (AAV1.9-3-HEK293-peptide-CMV-lacZ), and investigated their ability to transduce HEK293 cells. The peptides we displayed on the AAV1.9-3-CMV-lacZ vector were GRAKLA, RTPSRPP, RMAARTP, RLPAKAA and RTNKTSSQEKLA. All the peptides we tested could significantly restore the infectivity of rAAV1.9-3, although transduction efficiencies were only comparable to the efficiency attainable by a 10-fold lower dose of rAAV2 (Fig. 4). Nonetheless, this observation provides proof-of-principle of the rAAV1.9-3-based random peptide display library system.

\section{rAAV1.9-3-HEK293-peptide vectors transduced cells in a heparin receptor-independent manner}

AAV2 infects cells through the electrostatic interaction between negatively charged heparan sulfate proteoglycan (HSPG) on cell surface and positively charged heparin binding motif on the AAV2 capsid (Summerford and Samulski, 1998). Since the isoelectric points of the HEK293-targeting peptides were all in the basic range, we investigated a possibility that rAAV1.9-3-HEK293-peptide vectors transduced cells via HSPG binding, by a heparin inhibition assay using HEK293 cells. As expected, rAAV2-mediated transduction in HEK293 cells was inhibited in a heparin concentration-dependent manner (Fig. 5). In contrast, no inhibition was 
Table 1. Targeting peptides identified from rAAV1.9-3 random peptide display libraries.

\begin{tabular}{|c|c|c|c|c|c|}
\hline Cells & Experiment & Library $^{1}$ & Peptide $^{2}$ & Frequency $^{3}$ & $\mathrm{pI}$ \\
\hline \multirow[t]{36}{*}{ HEK293 } & \multirow[t]{8}{*}{1} & \multirow[t]{8}{*}{ 7-S-1 } & $\mathbf{R T P S R P P}$ & $3 / 18$ & 12.5 \\
\hline & & & LHTSRPA & $2 / 18$ & 10.6 \\
\hline & & & LKAGKQA & $2 / 18$ & 10.8 \\
\hline & & & RSSARGP & $1 / 18$ & 12.5 \\
\hline & & & $\mathbf{R S S S R A P}$ & $1 / 18$ & 12.5 \\
\hline & & & RSVHRAA & $1 / 18$ & 12.5 \\
\hline & & & RTPSRPS & $1 / 18$ & 12.5 \\
\hline & & & Others $^{4}$ & $7 / 18$ & \\
\hline & \multirow[t]{8}{*}{2} & \multirow[t]{8}{*}{$7-\mathrm{S}-2$} & RMAARTP & $4 / 20$ & 12.5 \\
\hline & & & RRSAAVP & $2 / 20$ & 12.5 \\
\hline & & & TRPARGA & $2 / 20$ & 12.5 \\
\hline & & & VGRAVGA & $2 / 20$ & 10.6 \\
\hline & & & GRSARGA & $1 / 20$ & 12.5 \\
\hline & & & KVAGRPP & $1 / 20$ & 11.7 \\
\hline & & & RNPGHHA & $1 / 20$ & 10.6 \\
\hline & & & Others ${ }^{4}$ & $7 / 20$ & \\
\hline & \multirow[t]{9}{*}{3} & \multirow[t]{9}{*}{$7-\mathrm{S}-3$} & RLPAKAA & $5 / 22$ & 11.7 \\
\hline & & & PSRERPP & $1 / 22$ & 10.5 \\
\hline & & & ALKPREP & $1 / 22$ & 9.7 \\
\hline & & & RAAGRPA & $1 / 22$ & 12.5 \\
\hline & & & RLPPVQA & $1 / 22$ & 10.6 \\
\hline & & & RMATTLP & $1 / 22$ & 10.6 \\
\hline & & & RMSSTLA & $1 / 22$ & 10.6 \\
\hline & & & RVAARGA & $1 / 22$ & 12.5 \\
\hline & & & Others $^{4}$ & $10 / 22$ & \\
\hline & \multirow[t]{5}{*}{4} & \multirow[t]{5}{*}{$12-\mathrm{S}-1$} & RSGKREERA & $5 / 11$ & 11.4 \\
\hline & & & DAGRSRTREMAA & $3 / 11$ & 10.3 \\
\hline & & & MRPNTVKVMGSP & $1 / 11$ & 11.7 \\
\hline & & & PVNVNRSP & $1 / 11$ & 10.6 \\
\hline & & & RGSGHQA & $1 / 11$ & 10.6 \\
\hline & \multirow[t]{2}{*}{5} & \multirow[t]{2}{*}{$12-\mathrm{S}-2$} & RTNKTSSQEKLA & $27 / 28$ & 10.8 \\
\hline & & & DRIMRLRGIGCP & $1 / 28$ & 10.4 \\
\hline & \multirow[t]{4}{*}{6} & \multirow[t]{4}{*}{$12-\mathrm{S}-3$} & GRAKLA & $16 / 20$ & 11.7 \\
\hline & & & TGSSPRGLSKQA & $2 / 20$ & 11.7 \\
\hline & & & NEGRAATRASAA & $1 / 20$ & 10.5 \\
\hline & & & RATGKGWNEKAP & $1 / 20$ & 10.8 \\
\hline \multirow[t]{8}{*}{$\mathrm{HDF}$} & \multirow[t]{4}{*}{7} & \multirow[t]{4}{*}{$7-\mathrm{S}-1$} & ARTGRSP & $22 / 26$ & 12.5 \\
\hline & & & SRNGRAP & $2 / 26$ & 12.5 \\
\hline & & & ARKGRAP & $1 / 26$ & 12.5 \\
\hline & & & SRNGRAP & $1 / 26$ & 12.5 \\
\hline & \multirow[t]{4}{*}{8} & \multirow[t]{4}{*}{$7-\mathrm{L}$} & GRTGRSP & $9 / 19$ & 12.5 \\
\hline & & & SKAGRSP & $8 / 19$ & 11.7 \\
\hline & & & ARSGRGA & $1 / 19$ & 12.5 \\
\hline & & & TRSGRTP & $1 / 19$ & 12.5 \\
\hline
\end{tabular}


Table 1. (Continued)

\begin{tabular}{ccllrr}
\hline Cells & Experiment & Library $^{1}$ & \multicolumn{1}{c}{ Peptide $^{2}$} & Frequency $^{3}$ & pI \\
\hline 9 & $12-$ S-1 & NRILEGMPAHHA & $28 / 28$ & 7.7 \\
& $12-L$ & TLNIIGRPDVQA & $23 / 24$ & 6.2 \\
& & ARTGRSP & $1 / 24$ & 12.5 \\
\hline
\end{tabular}

Note: ${ }^{17}$-S-1, 7-S-2, etc. indicate the identification numbers of different library lots produced separately. We produced three each different lots of 7-mer (7-S-1, 7-S-2 and 7-S-3) and 12-mer (12-S-1, 12-S-2 and 12-S-3) libraries on a small scale, and one each lot of 7-mer (7-L) and 12-mer (12-L) libraries on a large scale.

${ }^{2}$ Commonly shared amino acids are indicated in bold.

${ }^{3}$ Number of the clones carrying each peptide among the total number of clones in which the peptide sequences were determined.

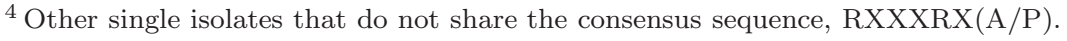

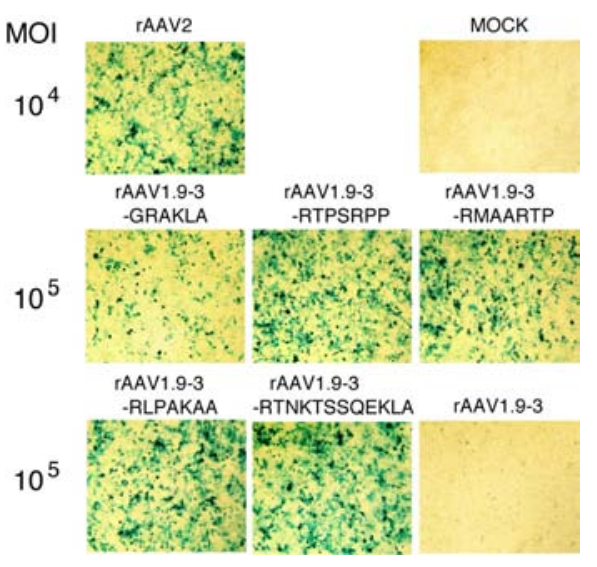

(a)

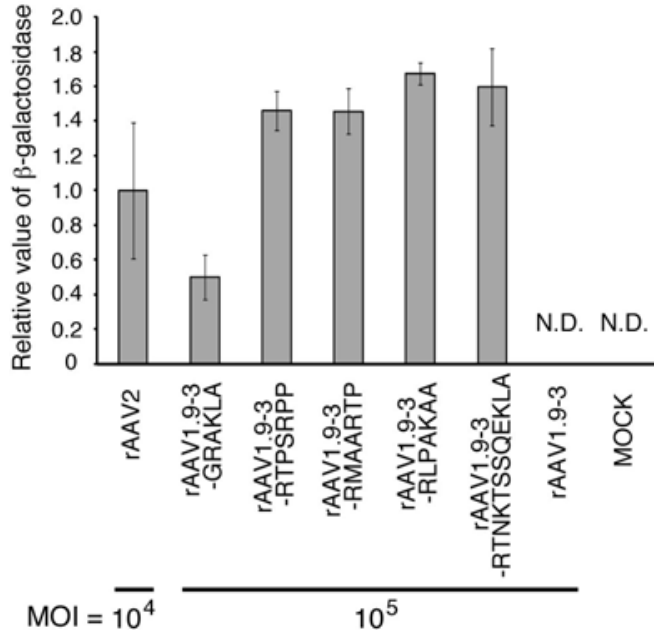

(b)

Fig. 4. Transduction efficiencies of AAV1.9-3-HEK293-peptide-CMV-lacZ vectors in HEK293 cells. HEK293 cells in 24-well plates were infected with AAV1.9-3-CMV-lacZ or AAV1.9-3-HEK293-peptide-CMV-lacZ vectors at an MOI of $10^{5}$ in quadruplicate, and subjected to (a). X-Gal staining (one well) and (b). $\beta$-Gal ELISA (three wells each). As reference controls, cells were infected with AAV2-CMV-lacZ at an MOI of $10^{4}$ or $10^{5}$. In Panel (b), the values represent relative amounts of $\beta$-Gal enzyme to that in the cells infected with AAV2-CMV-lacZ at an MOI of $10^{4}$. The mean value from the samples infected with AAV2-CMV-lacZ at an MOI of $10^{5}$ is $5.97 \pm 0.17$, which is not included in the figure. Vertical bars are SDs. N.D., not detected.

observed when cells were infected with any of the 5 rAAV1.9-3-HEK-peptide vectors (Fig. 5). Interestingly, the presence of heparin enhanced transduction with rAAV1.9-3-GRAKLA, although the mechanism is currently unknown. Nonetheless, the results demonstrate that rAAV1.9-3-HEK293-peptide vectors do not use the heparin receptor in transduction. 


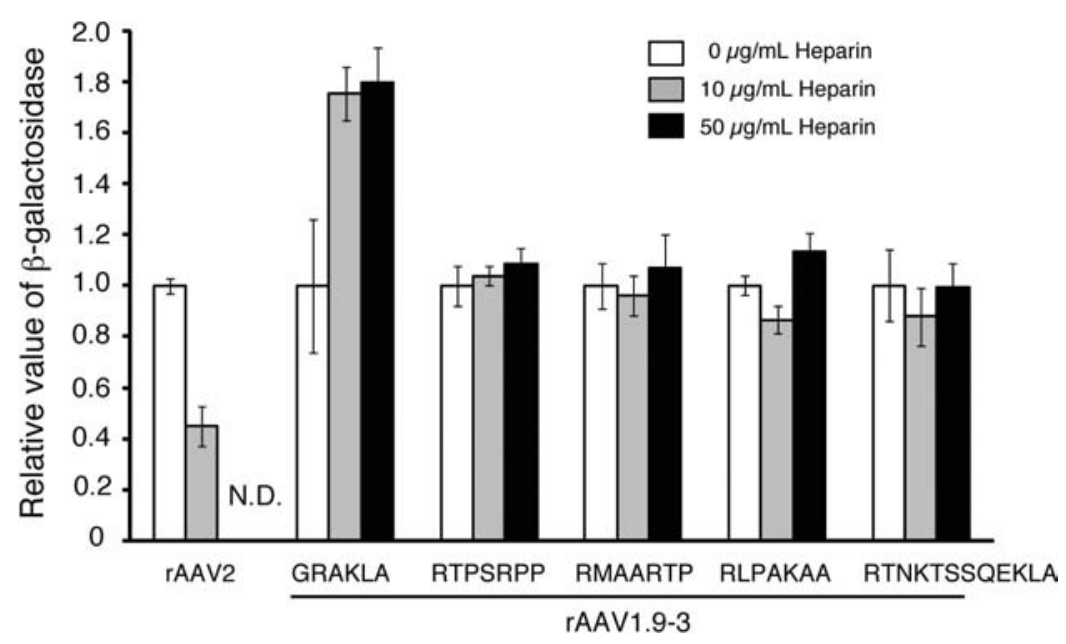

Fig. 5. Heparin receptor-independent transduction with rAAV1.9-3-HEK293-peptide vectors. HEK293 cells were infected with rAAV vectors to be tested (i.e., AAV2-CMV-lacZ and AAV1.9-3-HKE293-peptide-CMV-lacZ vectors) at an MOI of $10^{5}$ in the presence of heparin at three different concentrations $(0,10$ and $50 \mu \mathrm{g} / \mathrm{ml})$. Three days post-infection, transduction efficiencies were determined by $\beta$-Gal ELISA of cell lysates. The experiment was performed in triplicate. Values are transduction efficiencies relative to that of the $0 \mu \mathrm{g} / \mathrm{ml}$ control in each vector group. Vertical bars are SDs. N.D., not detected.

\section{Identification of primary normal human dermal fibroblasts (HDF)-targeting $r A A V 1.9-3$ variants}

To further validate the rAAV1.9-3-based random peptide display library system, we performed biopanning on HDF cells using the 7- and 12-mer libraries produced on small and large scales. HDF cells are resistant to transduction with rAAV1.9-3 as are other types of cells, and no appreciable transduction occurred when HDF cells were infected with dsAAV1.9-3-CMV-GFP at an MOI of $10^{5}$ (data not shown). Following three rounds of positive selection, 11 particular peptides were identified with a consensus sequence, XRXGR(A/S)P, being shared by 6 of them (Table 1). We first produced double-stranded dsAAV1.9-3-HDF-peptide-CMV-GFP vectors displaying each of the 6 enriched peptides (i.e., ARTGRSP, SRNGRAP, GRTGRSP, SKAGRSP, NRILEGMPAHHA and TLNIIGRPDVQA) on a small scale. Using unpurified rAAV vector preparations (i.e., HEK293 cell crude lysates), we investigated whether the display of the 7- or 12-mer peptides identified by the biopanning of the libraries can restore transduction in HDF cells. We found that all of the peptides successfully mediated transduction with the 7 -mers being more potent than the 12-mers. To further characterize them, three rAAV1.9-3-HDF-peptide vectors (i.e., rAAV1.9-3-GRTGRSP, rAAV1.9-3-SRNGRAP and rAAV1.9-3-SKAGRSP) containing the single-stranded AAV-CMV-GFP genome were produced on a large scale, purified as described in the materials and methods, and tested on HDF cells at an MOI of $10^{5}$. All the three rAAV1.9-3-HDF-peptide vectors transduced HDF 


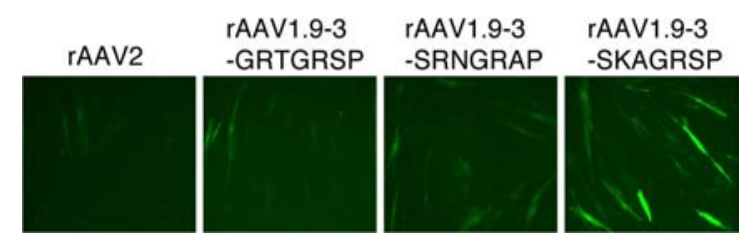

(a)

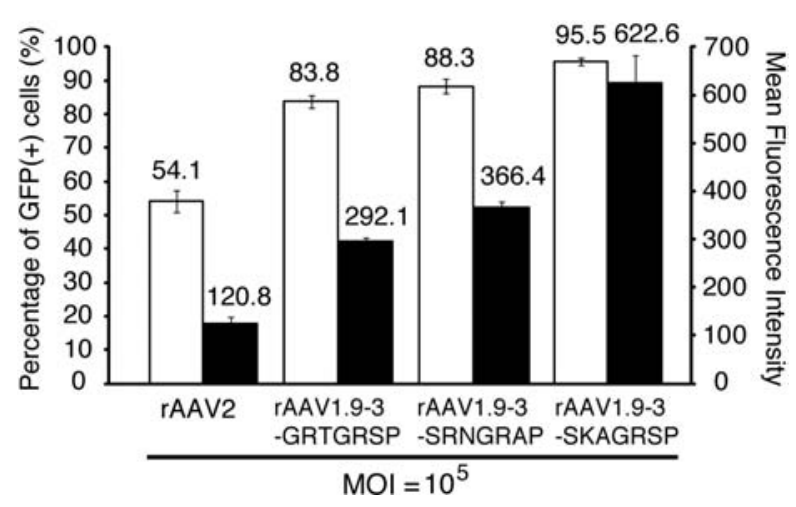

(b)

Fig. 6. Transduction efficiencies of single-stranded AAV1.9-3-HDF-peptide-CMVGFP vectors in HDF cells. HDF cells were infected with ssAAV2-CMV-GFP and ssAAV1.9-3HDF-peptide-CMV-GFP vectors at an MOI of $10^{5}$. Three days post-infection, GFP expression was assessed by fluorescence microscopy (a). and flow cytometry (b). The open and closed columns indicate percentage of GFP-positive cells and mean fluorescence intensity (MFI), respectively. The experiment was performed in triplicate. Vertical bars are SDs.

cells better than rAAV2, and one of them, rAAV1.9-3-SKAGRSP, directed as much as 5.2-fold higher transgene expression compared to rAAV2 (Fig. 6).

\section{rAAV1.9-3-HDF-peptide vectors transduced non-targeted HeLa cells with significantly reduced efficiency compared to $r A A V 2$}

As a further measure of potentially improved selectivity of rAAV1.9-3-HDF-peptide vectors, transduction efficiency was also investigated in HeLa cells. HeLa cells are commonly used as a control cell line to assess the degree of specificity of targeting rAAV vectors due to their high permissiveness to rAAV. All the three rAAV1.93-HDF-peptide vectors transduced HeLa cells at 3.2- to 6.1- and 5.7- to 15.8-fold lower efficiency than the control rAAV2 at an MOI of $10^{4}$ and $10^{3}$, respectively (Fig. 7). This indicates that the selected peptides from the libraries potentially possess specificity to the target cells.

All of these observations demonstrate that rAAV1.9-3, despite its infectiondefective nature, can serve as a platform for random peptide display libraries and 


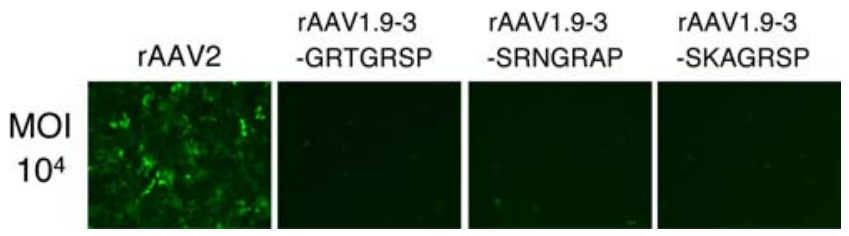

(a)

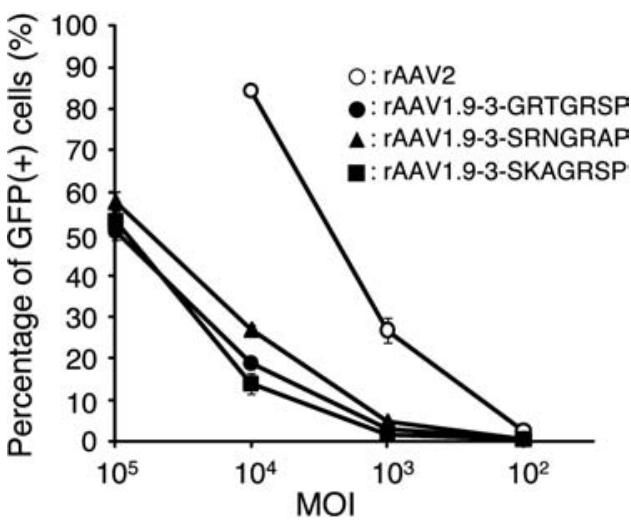

(b)

Fig. 7. Assessment of specificity of rAAV1.9-3-HDF-peptide vectors in non-targeted HeLa cells. HeLa cells were infected with ssAAV2-CMV-GFP or ssAAV1.9-3-HDF-peptide vectors at the indicated MOIs. Three days post-infection, GFP expression was assessed by fluorescence microscopy (a). and flow cytometry (b). Cells were infected at the indicated MOIs of ssAAV2CMV-GFP (open circle) and ssAAV1.9-3-HDF-peptide vectors (closed circle, triangle, and square) for 3 days and subjected to flow cytometry. The experiment was performed in triplicate. Vertical bars are SDs.

has an ability to not only restore but also substantially enhance transduction when an appropriate targeting peptide is expressed on its virion shell.

\section{Discussion}

\section{Platform rAAVs for peptide display}

To date rAAV2 has exclusively been used as a platform for peptide display, and only one study by Grimm et al. explored an alternative rAAV (i.e., AAV-DJ carrying an AAV2, 8 and 9 chimera capsid) as a platform (Grimm et al., 2008) (Table 2). Because not only inserted peptides but also the platform for their display could influence the biological properties of rAAV-peptide vectors, the choice of the platform should be critical. In this regard, our study showed that the infection-defective rAAV1.9-3 offers an alternative new peptide display platform that is naturally detargeted due to its impaired infectivity.

Non-infectious rAAV variants have been identified in previous studies (Lochrie et al., 2006b; Rabinowitz et al., 1999; Shen et al., 2007; Shi et al., 2001; 


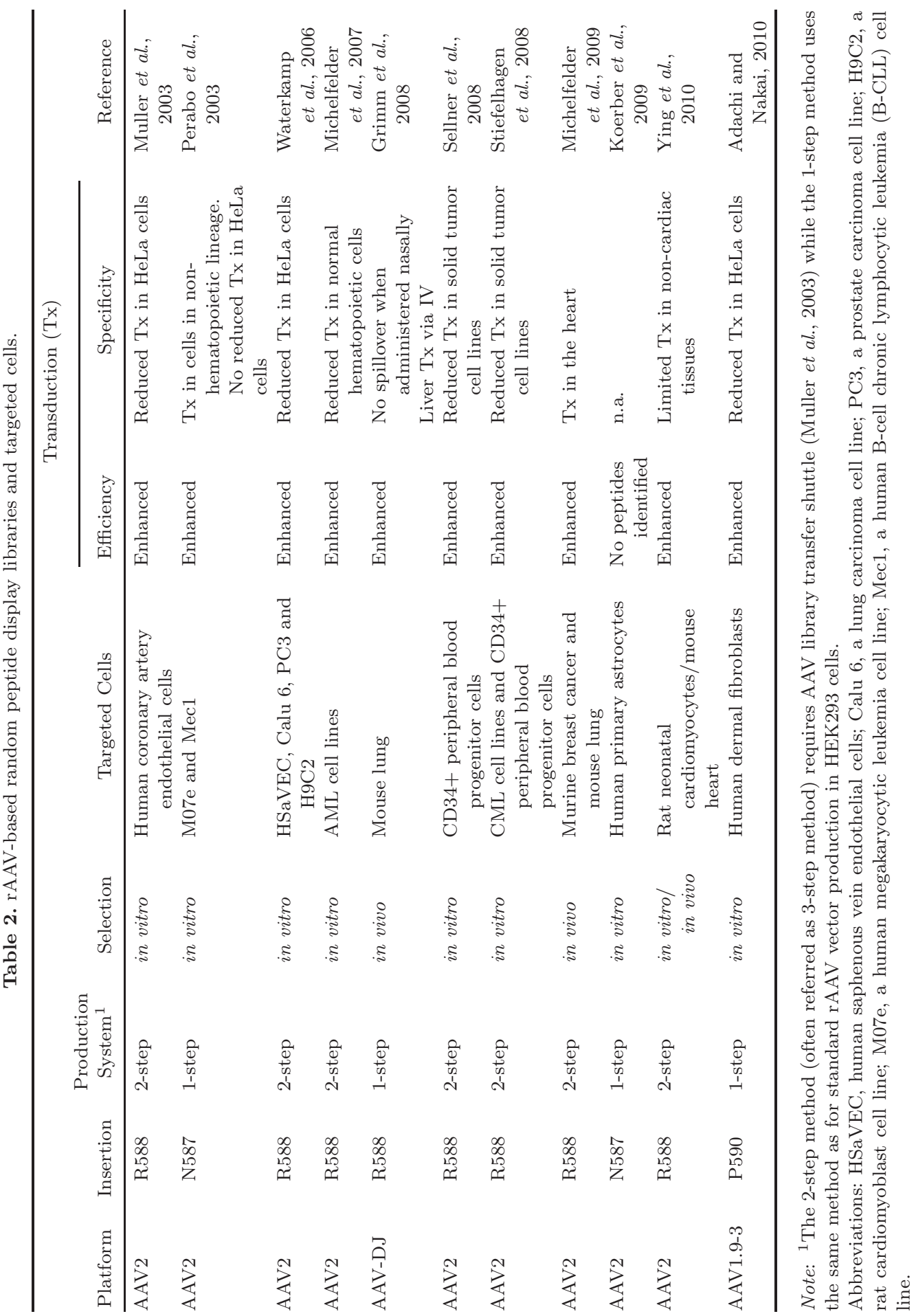


Wu et al., 2000), but none of the studies have exploited these defective variants as a platform for peptide display. In case of AAV2-derived mutants, loss of infectivity does not necessarily result from loss of binding to heparin, a soluble form of the AAV2 primary receptor on cell surface (Lochrie et al., 2006b; Opie et al., 2003; Rabinowitz et al., 1999). Likewise, loss of the ability to bind heparin does not always cause loss of infectivity (Kern et al., 2003; Shi et al., 2001; Ying et al., 2010). rAAV vector-mediated cell transduction is a multistep process that involves cell attachment (Summerford and Samulski, 1998), internalization (Summerford et al., 1999), intracellular trafficking (Bartlett et al., 2000; Ding et al., 2005), uncoating (Thomas et al., 2004), viral genome recombination (Duan et al., 1998; Nakai et al., 2000b), and chromatinization of the viral genome (Penaud-Budloo et al., 2008). A defect at any step described above could cause transduction incompetence. Unlike noninfectious variants identified by capsid mutagenesis, rAAV1.9-3 does not harbor point mutations in the capsid amino acid sequence. Rather it exhibits a simplest chimeric structure between two different naturally-occurring serotype capsids, and the N-terminus of the VP1 capsid containing the phospholipase A2 domain essential for virus infectivity (Girod et al., 2002) is not altered. Therefore, impaired infectivity of rAAV1.9-3 should not be due to a fundamental structural defect of the capsid protein but likely due to indirect disruption of a capsid functional domain (e.g., a domain that interacts with cell surface receptors) by a conformational change as a consequence of domain swapping. The present study per se did not address a question as to which step in the transduction process is impaired in the AAV1.9-3 capsid. However, we have observed that an RGD-4C peptide insertion into rAAV1.93 capsid at position 588 or 590 could restore infectivity to U87-MG cells expressing $\alpha \mathrm{v} \beta 3$ integrin (data not shown). Considering that the RGD-4C peptide is a wellestablished ligand to the cell surface integrin receptor (Koivunen et al., 1995; Shi and Bartlett, 2003), it is likely that the transduction-restoring peptides we identified serve as new cellular receptor attachment sites on the rAAV1.9-3 capsid.

\section{Locations of peptide display on the capsid}

Successful alteration of natural tropism of rAAV vectors by targeting peptide insertion in the capsid was first reported by Girod et al. in 1999 (Girod et al., 1999). This pioneering study performed before the establishment of the atomic structure of the AAV capsid, not only demonstrated proof-of-concept of the peptide insertion approach but also elucidated that a targeting ligand inserted at the AAV2 capsid position 587 was effectively presented on the surface of the capsid. Site-directed mutagenesis studies of the AAV2 capsid by Wu et al. and Shi et al. further confirmed that position 587 is exposed on the surface (Shi et al., 2001; Wu et al., 2000). This was finally validated in 2002 by Xie et al. who determined the atomic structure of the AAV2 capsid by X-ray crystallography (Xie et al., 2002). The defined tertiary structure of the capsid revealed that a.a. 587 is positioned at the peak of the 
three-fold protrusions of the AAV2 capsid and resides within the heparin binding motif R585-X-X-R587. Because of its topological location that allows a peptide to be effectively displayed and because of potential ablation of heparin binding ability by peptide insertion, position 587 and its adjacent position 588 of the AAV2 capsid have been preferred sites for peptide display (Table 2). The sites besides this vicinity that accommodate a peptide for effective tropism alteration include a.a.138 or 139 at the N-terminus of the VP2 protein (Loiler et al., 2003; Shi et al., 2001; Warrington et al., 2004), a.a. 161 within the unique VP1-VP2 overlap region (Shi et al., 2001), and a.a. 453 or 459 on the most prominent outer peak of the three-fold capsid protrusion (Boucas et al., 2009). Importantly, to redirect rAAV2 or other heparin-binding variants (e.g., rAAV-DJ) to target cells, it is critical to ablate heparin binding and abrogate natural tropism of the vector (Boucas et al., 2009; Grimm et al., 2008; Perabo et al., 2006b; Shi et al., 2006). In random peptide display libraries, the studies to date have exclusively selected the vicinity around the R585-X-X-R587 heparin binding motif for peptide insertion, and other potential sites have yet to be explored (Table 2).

\section{Methods for rAAV-peptide library production}

rAAV libraries, whether they are peptide display or DNA-shuffled libraries, can be produced either by the 1-step or 2-step method (Muller et al., 2003); the former uses a straightforward plasmid transfection in HEK293 cells while the latter involves production of AAV library transfer shuttles (Fig. 8). The transfer shuttles are mosaic particles composed of wild-type AAV2 and genetically engineered capsid proteins. Although the 2-step method is rather complicated and cumbersome, it minimizes the phenotype-genotype dissociation problem in the libraries. Earlier versions of rAAV2 peptide libraries produced by the 2-step method suffered from contamination of wild-type AAV2, which resulted from homologous recombination between rAAV2 helper plasmids and library plasmid and might deteriorate the quality or diversity of the libraries (Muller et al., 2003). However, this shortcoming has recently been overcome by the use of a new AAV2 helper plasmid with the least sequence homology to the library plasmid (Waterkamp et al., 2006). In our study, a modified 1-step method was used in which the quantity of rAAV library plasmid DNA to be transfected was significantly reduced by 10-100 fold compared to that of adenovirus helper plasmid (pHelper, Stratagene). A similar 1-step strategy was used by Maheshri et al. to minimize the phenotype-genotype dissociation (Maheshri et al., 2006), while others produced rAAV libraries by a 1-step method with no particular consideration for this issue (Grimm et al., 2008; Perabo et al., 2003). Nonetheless, the power of selection in biopanning allowed successful identification of new variants from libraries produced by either the 1-step or 2-step method, or even from unpurified libraries as demonstrated in this study. 
(a)

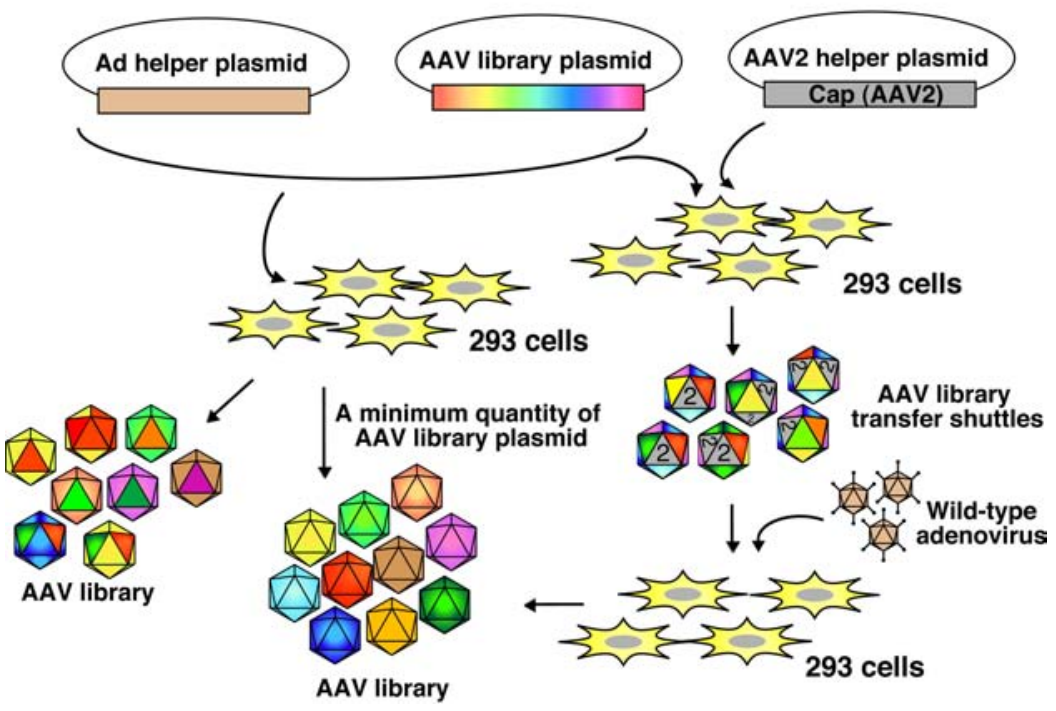

Fig. 8. Two methods for production of rAAV variant libraries. (a). 1-step method. AAV library plasmid and adenovirus helper plasmid are co-transfected into HEK293 cells. The mosaicism of capsid proteins can be minimized by limiting the quantity of AAV library plasmid used for transfection. (b). 2-step method. In the first step, HEK 293 cells are co-transfected with three plasmids including an AAV2 helper plasmid expressing the wild-type AAV2 capsid protein, resulting in the production of AAV library transfer shuttles. Viral coats of the transfer shuttles are composed of wild-type AAV2 and AAV variants capsid proteins. AAV libraries with minimum mosaicism can be obtained by infecting HEK293 cells with the transfer shuttles at a low MOI together with wild-type adenovirus.

\section{Targeting rA AV-peptide variants identified from libraries (Table 2)}

To our knowledge, 10 studies excluding ours have undertaken the rAAV random peptide display approach to identify new rAAV variants with desired properties or targeted phenotype (Grimm et al., 2008; Koerber et al., 2009; Michelfelder et al., 2009 and 2007; Muller et al., 2003; Perabo et al., 2003; Sellner et al., 2008; Stiefelhagen et al., 2008; Waterkamp et al., 2006; Ying et al., 2010). In vitro biopanning has been performed for a variety of target cells, many of which are known to be difficult to transduce with rAAV2 vectors such as endothelial cells, leukemic cells and astrocytes. The approach has recently been extended to the in vivo context to identify rAAV-peptide variants that target the lung, heart and breast tumor in murine models (Grimm et al., 2008; Michelfelder et al., 2009; Ying et al., 2010). Importantly, the studies could successfully identify rAAV-peptide variants with enhanced transduction efficiency and have shown that the enhancement was indeed mediated by interaction between the expressed peptides and cell surface receptors. However, the identity of cognate cellular receptors targeted by the peptides has yet to be determined. Consensus sequences of peptides have been identified for several targeting 
Table 3. Consensus sequences of targeting peptides identified from rAAV-peptide libraries.

\begin{tabular}{|c|c|c|c|c|}
\hline Reference & $\begin{array}{c}\text { Type of Target Cell or } \\
\text { Organ (Species) }\end{array}$ & Consensus Sequence $^{1}$ & $\mathrm{pI}$ & $\begin{array}{c}\text { Putative } \\
\text { Cellular } \\
\text { Receptor }^{2}\end{array}$ \\
\hline \multirow[t]{2}{*}{$\begin{array}{l}\text { Muller et al., } \\
\quad 2003\end{array}$} & $\begin{array}{c}\text { Endothelial cell } \\
\text { (human) }\end{array}$ & NSVRDL $(\mathrm{G} / \mathrm{S})$ & 6.2 & - \\
\hline & & NSVSS - (S/A) & 6.2 & - \\
\hline $\begin{array}{l}\text { Perabo et al., } \\
\quad 2003\end{array}$ & $\begin{array}{l}\text { Myeloid leukemia cell } \\
\text { (human) }\end{array}$ & RGD - - - - & 6.2 & Integrin \\
\hline \multirow[t]{3}{*}{$\begin{array}{l}\text { Waterkamp } \\
\text { et al., } 2006\end{array}$} & $\begin{array}{l}\text { Venous endothelial } \\
\text { cell (human) }\end{array}$ & $\mathrm{N}--(\mathrm{R} / \mathrm{Q})-\cdots$ & $4.1-6.3$ & - \\
\hline & $\begin{array}{l}\text { Lung carcinoma } \\
\text { (mouse) }\end{array}$ & $-(P / S)--R P-$ & 10.5 & - \\
\hline & $\begin{array}{l}\text { Prostate carcinoma } \\
\text { cell (human) }\end{array}$ & $(\mathrm{D} / \mathrm{R})(\mathrm{L} / \mathrm{G}) \cdots$ & 6.2 & - \\
\hline $\begin{array}{l}\text { Michelfelder } \\
\text { et al., } 2007\end{array}$ & $\begin{array}{l}\text { Acute myeloid } \\
\text { leukemia cell } \\
\text { (human) }\end{array}$ & $\mathrm{N}-(\mathrm{T} / \mathrm{V})-\cdots$ & $6.0-10.5$ & - \\
\hline \multirow{2}{*}{$\begin{array}{l}\text { Grimm et al., } \\
2008\end{array}$} & Lung (mouse) & $\ldots-(R / G) \ldots$ & 6.2 & - \\
\hline & Liver (mouse) & $(\mathrm{N} / \mathrm{G})-\mathrm{G}-\mathrm{G}--$ & 6.3 & - \\
\hline $\begin{array}{l}\text { Sellner et al., } \\
\quad 2008\end{array}$ & $\begin{array}{l}\text { Primary CD34+ } \\
\text { PBMC (human) }\end{array}$ & $\mathrm{N}-\cdots--$ & $6.0-6.3$ & - \\
\hline $\begin{array}{l}\text { Stiefelhagen } \\
\text { et al., } 2008\end{array}$ & $\begin{array}{l}\text { Chronic myelogenous } \\
\text { leukemia cell } \\
\text { (human) }\end{array}$ & $-\cdots(\mathrm{R} / \mathrm{L})--$ & $6.0-10.5$ & - \\
\hline \multirow{2}{*}{$\begin{array}{l}\text { Michelfelder } \\
\text { et al., } 2009\end{array}$} & Lung (mouse) & $\operatorname{PRSAD}(\mathrm{D} / \mathrm{L})(\mathrm{A} / \mathrm{S})$ & 6.2 & - \\
\hline & $\begin{array}{l}\text { Primary breast cancer } \\
\text { cell (mouse) }\end{array}$ & RGD - - - - & $6.2-6.5$ & Integrin \\
\hline \multirow{2}{*}{$\begin{array}{l}\text { Ying et al., } \\
\qquad 2010\end{array}$} & Heart (mouse) & $\cdots(P / R)-P$ & 10.5 & - \\
\hline & $\begin{array}{l}\text { Neonatal } \\
\text { cardiomyocyte } \\
\text { (rat) }\end{array}$ & $-\cdots(R / L)-P$ & $9.7-10.5$ & - \\
\hline \multirow{2}{*}{$\begin{array}{l}\text { Adachi and } \\
\text { Nakai, } 2010\end{array}$} & HEK293 cell (human) & $\mathrm{R}--\mathrm{R}-(\mathrm{A} / \mathrm{P})$ & 12.5 & - \\
\hline & $\begin{array}{l}\text { Dermal fibroblast } \\
\text { (human) }\end{array}$ & $-\mathrm{R}-\mathrm{GR}(\mathrm{A} / \mathrm{S}) \mathrm{P}$ & 12.5 & - \\
\hline
\end{tabular}

Note: ${ }^{1} 7$-mer peptide sequences are shown with one or more consensus amino acids. 2 "_." indicates unknown.

ligands (Table 3), providing some insights into the targeting mechanism. All but one of the peptides we identified in this study were positively charged with isoelectric points of 9.7 to 12.5 , indicating potential electrostatic interactions with not-yetidentified cell surface receptors. In addition, the last amino acid within the 7-mer and 12-mer peptide insertions selected for HEK 293 and HDF cells was exclusively alanine $(\mathrm{A})$ or proline $(\mathrm{P})$, indicating a critical role of these neutral, non-polar amino acids in viral infectivity (Table 1 ). 


\section{Current problems and perspectives on $r A A V$-based random peptide display systems}

Although the directed evolution combined with positive selection has provided a powerful means to identify rAAV variants with significantly altered tropism and enhanced transduction efficiency, it has been difficult to completely avoid off-target transduction. This might be in part attributed to the lack of effective means to undertake simultaneous negative selection at present. Additionally, it might be a reflection of an inevitable biological propensity of the platform that has been currently in use (e.g., rAAV2). In fact, a recent in vivo study has highlighted that detargeting the heart with rAAV2-based variants remains a significant challenge due to the ability of rAAV2 to transduce cells via heparin binding-independent transduction pathways (Michelfelder et al., 2009). These observations underscore the need of the development of new detargeted platform for peptide display as well as effective strategies for negative selection.

Although we did not address DNA-shuffling or random mutagenesis libraries in this article, there has been a significant progress in these approaches as well toward successful molecular evolution of the AAV capsids. With the most advanced techniques, Excoffon et al. identified AAV2.5T, a DNA-shuffled AAV2 and AAV5 hybrid with an A581T mutation, that transduces human airway epithelia from their apical surface with high efficiency (Excoffon et al., 2009); and Yang et al. reported AAVM41, a heart-targeting variant with AAV1, 6, 7 and 8 capsids being shuffled (Yang et al., 2009). More recently, Schaffer and colleagues have established a combinatorial approach that utilizes highly diverse rAAV libraries generated by error-prone PCR, DNA shuffling, AAV peptide display, and semi-random loop replacement in conjunction with successive diversification (Koerber et al., 2009). Rapidly increasing knowledge about the AAV capsid structures and serotypedependent biology will further advance the rational design approaches, which, in combination with the directed evolution approaches, would eventually lead to the development of more effective way to evolve AAV into an ultimate gene delivery vector.

In summary, rAAV-based random peptide display library approaches have been proven to be extremely effective in identifying new rAAV variants with altered tropism and/or enhanced transduction efficiency; however, they are currently facing a fundamental limitation that off-target transduction is often considerable. Although the data presented in this article are preliminary, our results warrant further studies into whether the use of next generation platforms for peptide display, such as the naturally detargeted rAAV1.9-3 we report here, might offer a solution to the current drawbacks of the directed evolution approaches.

\section{Acknowledgments}

We thank Guangping Gao and James M. Wilson for providing AAV serotype 9 packaging plasmid, Xiao Xiao for pEMBL-CMV-GFP plasmid, Masato Yamamoto 
for wild-type adenovirus type 5, Yunqing Kan and Nicole Kotchey for technical assistance, and Christopher S. Naitza for assistance in the preparation of the manuscript. This work was supported by a Public Health Service grant DK78388 and a Cystic Fibrosis Foundation Research Development Program grant (R883CR02).

\section{References}

Arbetman, A. E., Lochrie, M., Zhou, S., Wellman, J., Scallan, C. et al. (2005). Novel caprine adeno-associated virus (AAV) capsid (AAV-Go.1) is closely related to the primate AAV-5 and has unique tropism and neutralization properties. J Virol, 79: $15238-15245$.

Bartlett, J. S., Wilcher, R. and Samulski, R. J. (2000). Infectious entry pathway of adenoassociated virus and adeno-associated virus vectors. J Virol, 74: 2777-2785.

Boucas, J., Lux, K., Huber, A., Schievenbusch, S., Von Freyend, M. J. et al. (2009). Engineering adeno-associated virus serotype 2-based targeting vectors using a new insertion site-position 453-and single point mutations. J Gene Med, 11: 1103-1113.

Burton, M., Nakai, H., Colosi, P., Cunningham, J., Mitchell, R. et al. (1999). Coexpression of factor VIII heavy and light chain adeno-associated viral vectors produces biologically active protein. Proc Natl Acad Sci USA, 96: 12725-12730.

Ding, W., Zhang, L., Yan, Z. and Engelhardt, J. F. (2005). Intracellular trafficking of adeno-associated viral vectors. Gene Ther, 12: 873-880.

Duan, D., Sharma, P., Yang, J., Yue, Y., Dudus, L. et al. (1998). Circular intermediates of recombinant adeno-associated virus have defined structural characteristics responsible for long-term episomal persistence in muscle tissue. J Virol, 72: 8568-8577.

Excoffon, K. J., Koerber, J. T., Dickey, D. D., Murtha, M., Keshavjee, S. et al. (2009). Directed evolution of adeno-associated virus to an infectious respiratory virus. Proc Natl Acad Sci USA, 106: 3865-3870.

Foust, K. D., Nurre, E., Montgomery, C. L., Hernandez, A., Chan, C. M. et al. (2009). Intravascular AAV9 preferentially targets neonatal neurons and adult astrocytes. Nat Biotechnol, 27: 59-65.

Gao, G., Vandenberghe, L. H., Alvira, M. R., Lu, Y., Calcedo, R. et al. (2004). Clades of Adeno-associated viruses are widely disseminated in human tissues. J Virol, 78: 6381-6388.

Gao, G. P., Alvira, M. R., Wang, L., Calcedo, R., Johnston, J. et al. (2002). Novel adenoassociated viruses from rhesus monkeys as vectors for human gene therapy. Proc Natl Acad Sci USA, 99: 11854-11859.

Ghosh, A., Yue, Y., Long, C., Bostick, B. and Duan, D. (2007). Efficient wholebody transduction with trans-splicing adeno-associated viral vectors. Mol Ther, 15: $750-755$.

Girod, A., Ried, M., Wobus, C., Lahm, H., Leike, K. et al. (1999). Genetic capsid modifications allow efficient re-targeting of adeno-associated virus type 2. Nat Med, 5: $1052-1056$.

Girod, A., Wobus, C. E., Zadori, Z., Ried, M., Leike, K. et al. (2002). The VP1 capsid protein of adeno-associated virus type 2 is carrying a phospholipase A2 domain required for virus infectivity. J Gen Virol, 83: 973-978.

Grimm, D., Lee, J. S., Wang, L., Desai, T., Akache, B. et al. (2008). In vitro and in vivo gene therapy vector evolution via multispecies interbreeding and retargeting of adenoassociated viruses. J Virol, 82: 5887-5911. 
Grimm, D., Zhou, S., Nakai, H., Thomas, C. E., Storm, T. A. et al. (2003). Preclinical in vivo evaluation of pseudotyped adeno-associated virus vectors for liver gene therapy. Blood, 102: 2412-2419.

Inagaki, K., Fuess, S., Storm, T. A., Gibson, G. A., Mctiernan, C. F. et al. (2006). Robust systemic transduction with AAV9 vectors in mice: efficient global cardiac gene transfer superior to that of AAV8. Mol Ther, 14: 45-53.

Kern, A., Schmidt, K., Leder, C., Muller, O. J., Wobus, C. E. et al. (2003). Identification of a heparin-binding motif on adeno-associated virus type 2 capsids. $J$ Virol, 77: 11072-11081.

Koerber, J. T., Klimczak, R., Jang, J. H., Dalkara, D., Flannery, J. G. et al. (2009). Molecular evolution of adeno-associated virus for enhanced glial gene delivery. Mol Ther, 17: 2088-2095.

Koivunen, E., Wang, B. and Ruoslahti, E. (1995). Phage libraries displaying cyclic peptides with different ring sizes: ligand specificities of the RGD-directed integrins. Biotechnology (NY), 13: 265-270.

Li, W., Asokan, A., Wu, Z., Van Dyke, T., Diprimio, N. et al. (2008). Engineering and selection of shuffled AAV genomes: a new strategy for producing targeted biological nanoparticles. Mol Ther, 16: 1252-1260.

Li, W., Zhang, L., Johnson, J. S., Zhijian, W., Grieger, J. C. et al. (2009). Generation of Novel AAV Variants by Directed Evolution for Improved CFTR Delivery to Human Ciliated Airway Epithelium. Mol Ther, 17: 2067-2077.

Lochrie, M. A., Tatsuno, G. P., Arbetman, A. E., Jones, K., Pater, C. et al. (2006a). Adenoassociated virus (AAV) capsid genes isolated from rat and mouse liver genomic DNA define two new AAV species distantly related to AAV-5. Virology, 353: 68-82.

Lochrie, M. A., Tatsuno, G. P., Christie, B., Mcdonnell, J. W., Zhou, S. et al. (2006b). Mutations on the external surfaces of adeno-associated virus type 2 capsids that affect transduction and neutralization. J Virol, 80: 821-834.

Loiler, S. A., Conlon, T. J., Song, S., Tang, Q., Warrington, K. H. et al. (2003). Targeting recombinant adeno-associated virus vectors to enhance gene transfer to pancreatic islets and liver. Gene Ther, 10: 1551-1558.

Maguire, C. A., Gianni, D., Meijer, D. H., Shaket, L. A., Wakimoto, H. et al. (2009). Directed evolution of adeno-associated virus for glioma cell transduction. J Neurooncol, 96: 337-347.

Maersch, S., Huber, A., Buning, H., Hallek, M. and Perabo, L. (2010). Optimization of stealth adeno-associated virus vectors by randomization of immunogenic epitopes. Virology, 397: 167-175.

Maheshri, N., Koerber, J. T., Kaspar, B. K. and Schaffer, D. V. (2006). Directed evolution of adeno-associated virus yields enhanced gene delivery vectors. Nat Biotechnol, 24: 198-204.

Michelfelder, S., Kohlschutter, J., Skorupa, A., Pfennings, S., Muller, O. et al. (2009). Successful expansion but not complete restriction of tropism of adeno-associated virus by in vivo biopanning of random virus display Peptide libraries. PLoS One, 4: e5122.

Michelfelder, S., Lee, M. K., Delima-Hahn, E., Wilmes, T., Kaul, F. et al. (2007). Vectors selected from adeno-associated viral display peptide libraries for leukemia cell-targeted cytotoxic gene therapy. Exp Hematol, 35: 1766-1776.

Mori, S., Wang, L., Takeuchi, T. and Kanda, T. (2004). Two novel adeno-associated viruses from cynomolgus monkey: pseudotyping characterization of capsid protein. Virology, 330: $375-383$.

Muller, O. J., Kaul, F., Weitzman, M. D., Pasqualini, R., Arap, W. et al. (2003). Random peptide libraries displayed on adeno-associated virus to select for targeted gene therapy vectors. Nat Biotechnol, 21: 1040-1046. 
Muller, O. J., Leuchs, B., Pleger, S. T., Grimm, D., Franz, W. M. et al. (2006). Improved cardiac gene transfer by transcriptional and transductional targeting of adeno-associated viral vectors. Cardiovasc Res, 70: 70-78.

Nakai, H., Storm, T. A. and Kay, M. A. (2000a). Increasing the size of rAAV-mediated expression cassettes in vivo by intermolecular joining of two complementary vectors. Nat Biotechnol, 18: 527-532.

Nakai, H., Storm, T. A. and Kay, M. A. (2000b). Recruitment of single-stranded recombinant adeno-associated virus vector genomes and intermolecular recombination are responsible for stable transduction of liver in vivo. J Virol, 74: 9451-9463.

Nakai, H., Wu, X., Fuess, S., Storm, T. A., Munroe, D. et al. (2005). Large-scale molecular characterization of adeno-associated virus vector integration in mouse liver. $J$ Virol, 79: 3606-3614.

Opie, S. R., Warrington, K. H., Jr., Agbandje-Mckenna, M., Zolotukhin, S. and Muzyczka, N. (2003). Identification of amino acid residues in the capsid proteins of adenoassociated virus type 2 that contribute to heparan sulfate proteoglycan binding. $J$ Virol, 77: 6995-7006.

Pacak, C. A., Mah, C. S., Thattaliyath, B. D., Conlon, T. J., Lewis, M. A. et al. (2006). Recombinant adeno-associated virus serotype 9 leads to preferential cardiac transduction in vivo. Circ Res, 99: e3-9.

Penaud-Budloo, M., Le Guiner, C., Nowrouzi, A., Toromanoff, A., Cherel, Y. et al. (2008). Adeno-associated virus vector genomes persist as episomal chromatin in primate muscle. J Virol, 82: 7875-7885.

Perabo, L., Buning, H., Kofler, D. M., Ried, M. U., Girod, A. et al. (2003). In vitro selection of viral vectors with modified tropism: the adeno-associated virus display. Mol Ther, 8: 151-157.

Perabo, L., Endell, J., King, S., Lux, K., Goldnau, D. et al. (2006a). Combinatorial engineering of a gene therapy vector: directed evolution of adeno-associated virus. $J$ Gene Med, 8: 155-162.

Perabo, L., Goldnau, D., White, K., Endell, J., Boucas, J. et al. (2006b). Heparan sulfate proteoglycan binding properties of adeno-associated virus retargeting mutants and consequences for their in vivo tropism. J Virol, 80: 7265-7269.

Rabinowitz, J. E., Bowles, D. E., Faust, S. M., Ledford, J. G., Cunningham, S. E. et al. (2004). Cross-dressing the virion: the transcapsidation of adeno-associated virus serotypes functionally defines subgroups. J Virol, 78: 4421-4432.

Rabinowitz, J. E., Xiao, W. and Samulski, R. J. (1999). Insertional mutagenesis of AAV2 capsid and the production of recombinant virus. Virology, 265: 274-285.

Sarkar, R., Mucci, M., Addya, S., Tetreault, R., Bellinger, D. A. et al. (2006). Long-term efficacy of adeno-associated virus serotypes 8 and 9 in hemophilia a dogs and mice. Hum Gene Ther, 17: 427-439.

Schmidt, M., Katano, H., Bossis, I. and Chiorini, J. A. (2004). Cloning and characterization of a bovine adeno-associated virus. J Virol, 78: 6509-6516.

Sellner, L., Stiefelhagen, M., Kleinschmidt, J. A., Laufs, S., Wenz, F. et al. (2008). Generation of efficient human blood progenitor-targeted recombinant adeno-associated viral vectors (AAV) by applying an AAV random peptide library on primary human hematopoietic progenitor cells. Exp Hematol, 36: 957-964.

Shen, X., Storm, T. and Kay, M. A. (2007). Characterization of the relationship of AAV capsid domain swapping to liver transduction efficiency. Mol Ther, 15: 1955-1962.

Shi, W., Arnold, G. S. and Bartlett, J. S. (2001). Insertional mutagenesis of the adenoassociated virus type 2 (AAV2) capsid gene and generation of AAV2 vectors targeted to alternative cell-surface receptors. Hum Gene Ther, 12: 1697-1711. 
Shi, W. and Bartlett, J. S. (2003). RGD inclusion in VP3 provides adeno-associated virus type 2 (AAV2)-based vectors with a heparan sulfate-independent cell entry mechanism. Mol Ther, 7: 515-525.

Shi, X., Fang, G., Shi, W. and Bartlett, J. S. (2006). Insertional mutagenesis at positions 520 and 584 of adeno-associated virus type 2 (AAV2) capsid gene and generation of AAV2 vectors with eliminated heparin- binding ability and introduced novel tropism. Hum Gene Ther, 17: 353-361.

Stiefelhagen, M., Sellner, L., Kleinschmidt, J. A., Jauch, A., Laufs, S. et al. (2008). Application of a haematopoetic progenitor cell-targeted adeno-associated viral (AAV) vector established by selection of an AAV random peptide library on a leukaemia cell line. Genet Vaccines Ther, 6: 12.

Summerford, C., Bartlett, J. S. and Samulski, R. J. (1999). AlphaVbeta5 integrin: a coreceptor for adeno-associated virus type 2 infection. Nat Med, 5: 78-82.

Summerford, C. and Samulski, R. J. (1998). Membrane-associated heparan sulfate proteoglycan is a receptor for adeno-associated virus type 2 virions. J Virol, 72: 1438-1445.

Thomas, C. E., Storm, T. A., Huang, Z. and Kay, M. A. (2004). Rapid uncoating of vector genomes is the key to efficient liver transduction with pseudotyped adeno-associated virus vectors. J Virol, 78: 3110-3122.

Vandendriessche, T., Thorrez, L., Acosta-Sanchez, A., Petrus, I., Wang, L. et al. (2007). Efficacy and safety of adeno-associated viral vectors based on serotype 8 and 9 vs. lentiviral vectors for hemophilia B gene therapy. J Thromb Haemost 5: 16-24.

Wang, Z., Zhu, T., Qiao, C., Zhou, L., Wang, B. et al. (2005). Adeno-associated virus serotype 8 efficiently delivers genes to muscle and heart. Nat Biotechnol, 23: 321-328.

Warrington, K. H., Jr., Gorbatyuk, O. S., Harrison, J. K., Opie, S. R., Zolotukhin, S. et al. (2004). Adeno-associated virus type 2 VP2 capsid protein is nonessential and can tolerate large peptide insertions at its $\mathrm{N}$ terminus. J Virol, 78: 6595-6609.

Waterkamp, D. A., Muller, O. J., Ying, Y., Trepel, M. and Kleinschmidt, J. A. (2006). Isolation of targeted AAV2 vectors from novel virus display libraries. J Gene Med, 8: 1307-1319.

Wobus, C. E., Hugle-Dorr, B., Girod, A., Petersen, G., Hallek, M. et al. (2000). Monoclonal antibodies against the adeno-associated virus type $2(\mathrm{AAV}-2)$ capsid: epitope mapping and identification of capsid domains involved in AAV-2-cell interaction and neutralization of AAV-2 infection. J Virol, 74: 9281-9293.

Wu, P., Xiao, W., Conlon, T., Hughes, J., Agbandje-Mckenna, M. et al. (2000). Mutational analysis of the adeno-associated virus type 2 (AAV2) capsid gene and construction of AAV2 vectors with altered tropism. $J$ Virol, 74: 8635-8647.

Xie, Q., Bu, W., Bhatia, S., Hare, J., Somasundaram, T. et al. (2002). The atomic structure of adeno-associated virus (AAV-2), a vector for human gene therapy. Proc Natl Acad Sci USA, 99: 10405-10410.

Yang, L., Jiang, J., Drouin, L. M., Agbandje-Mckenna, M., Chen, C. et al. (2009). A myocardium tropic adeno-associated virus (AAV) evolved by DNA shuffling and in vivo selection. Proc Natl Acad Sci USA, 106: 3946-3951.

Ying, Y., Muller, O. J., Goehringer, C., Leuchs, B., Trepel, M. et al. (2010). Heart-targeted adeno-associated viral vectors selected by in vivo biopanning of a random viral display peptide library. Gene Ther, 17: 980-990. 